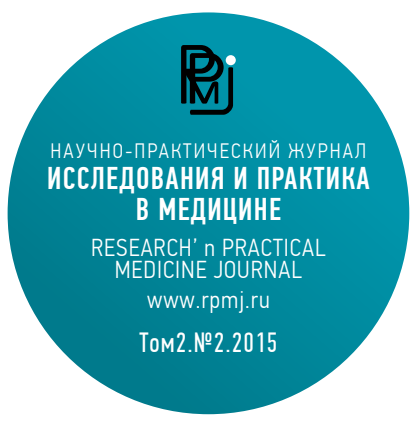

Ключевые слова:

метастазы в головном мозге, внутричерепные новообразования

Keywords:

brain metastases, central nervous system metastases, intracranial metastases

DOI: 10.17709/2409-2231-2015-2-2-8-14

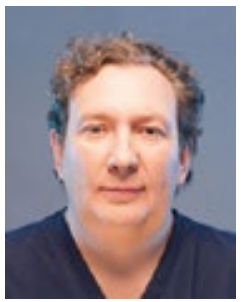

Для корреспонденции: Зайцев Антон Михайлович,

к.М.Н., заведующий отделением нейрохирургии

МНИОИ им. П.А. Герцена - филиала ФГБУ «НМИРЦ» Минздрава России

Адрес: 125284, Российская Федерация,

Москва, 2-ой Боткинский проезд, д. 3 ,

E-mail:azaitsev_nsi@mail.ru

Статья поступила 03.03.2015

принята к печати 11.06.2015

For correspondence:

Zaytsev Anton Mikhailovich - PhD, head of

neurosurgery department of P. Hertsen MORI

Address: 2-y Botkinskiy proezd, d.3,

Moskva, 125284, Russia

E-mail: azaitsev_nsi@mail.ru

The article was received 03.03.2015

accepted for publication 11.06.2015

\section{ЛЕЧЕНИЕ МЕТАСТАТИЧЕСКОГО ПОРАЖЕНИЯ ГОЛОВНОГО МОЗГА}

\author{
Зайцев А.М., Куржупов М.И., Потапова Е.А., Кирсанова О.Н.
}

МНИОИ им. П.А. Герцена - филиал ФГБУ «НМИРЦ» Минздрава России

125284, Российская Федерация, г. Москва, 2-ой Боткинский проезд, дом 3

\section{Резюме:}

Цель. Увеличение выживаемости больных с вторичным поражением головного мозга, а также выявление факторов благоприятного и негативного прогноза.

Материалы и методы. В ФГБУ МНИОИ им. П. А. Герцена Минздрава России с 2007 по 2013 гг было пролечено 268 больных с метастазами в головном мозге. Средний возраст составлял 55,8 лет (от 24 до 81 года). Метастазы колоректального рака выявлены в 7,8\% случаев, рака лёгкого в 34\%, меланомы кожи в 9,3\%, рака молочной железы в 26\%, рака почки в $11 \%$, без выявленного первичного очага в 4,5\%, на другие опухоли приходилось 6,7\%. Солитарный метастаз диагностирован у 164 (61,19\%) пациента, олигометастазы (2-3) - у 72 (26,87\%) больных, множественные метастазы (более 3) - у 32 (11,94\%) больных. У 106 (39,55\%) больных метастатическое поражение головного мозга было единственным проявлением генерализации процесса. С целью контроля радикальности удаления опухоли у 93 (34,7\%) больных использовался метод флуоресцентной навигации (ФД) с препаратом Аласенс. у 66 (24,6\%) больных интраоперационно проводился сеанс фотодинамической терапии (ФДТ). В 212 (79,1\%) случаях удаление метастаза выполнено тотально, у 55 (20,9\%) больных констатировано субтотальное удаление.

Результаты. Период наблюдения за больными составил от 3 до 79 месяцев. Медиана выживаемости среди всей группы больных с метастатическим поражением головного мозга составила 12 месяцев. Общая выживаемость достоверно зависела от RPA класса, объёма проведённого послеоперационного лечения, гистологического типа первичной опухоли, количества внутримозговых метастазов и сроках безрецидивного периода.

Выводы. Факторами, влияющими на общую выживаемость являются особенности гистологии первичного очага, множественность метастатического поражения, RPA класс и синхронный характер метастазирования. Медиана общей выживаемости больных, не получавших после хирургического лечения иного вида терапии, составила всего 4 месяца. При использовании комбинированного лечения (хирургическое лечение с облучением всего головного мозга) медиана выживаемости составляла 9-10,5 месяцев (в зависимости от метода облучения). При применении лекарственного лечения медиана общей выживаемости составила 11 месяцев. При комплексном лечении показатели выживаемости были наиболее высокими - 12 месяцев.

\section{TREATMENT OF METASTATIC BRAIN LESION}

Zaytsev A.M., Kurzhupov M.I., Potapova E.A., Kirsanova O.N.

P. Hertsen MORI

2-y Botkinskiy proezd, d.3, Moskva, 125284, Russia

\section{Abstract}

Objective. Increasing survival in patients with secondary brain damage, and identifying the factors of favorable and adverse prognosis.

Material and method. In P. A. Hertsen Moscow Oncology Research Institute 
from 2007 to 2013 there were treated 268 patients with brain metastases. The mean age was 55.8 years (from 24 to 81 years). Metastases of colorectal cancer identified in $7.8 \%$, cases of lung cancer in $34 \%$, melanoma $9.3 \%$, breast cancer in $26 \%$, kidney cancer in $11 \%$, with non-identified primary tumor in $4.5 \%$, other tumors accounted for $6.7 \%$. Solitary metastasis was diagnosed in $164(61,19 \%)$ patients, oligometastasis (2$3)-72(26,87 \%)$ patients with polymetastasis (more than $3)-32(11,94 \%)$ patients. In $106(39,55 \%)$ of patients with brain metastases it was the only manifestation of the generalization process. To control the radical removal of the tumor in $93(34,7 \%)$ patients we used the method of fluorescence navigation (FN) with the drug Alasens. In $66(24,6 \%)$ patients intraoperatively was held a session of photodynamic therapy (PDT). In 212 (79,1\%) cases, the removal of metastasis performed totally, 55 (20,9\%) patients stated Subtotal removal.

Results. The observation period for the patients ranged from 3 to 79 months. Survival median among the entire group of patients with metastatic brain lesion was 12 months. Overall survival was significantly dependent on RPA class, the volume of postoperative treatment, histological type of primary tumor, number of intracerebral metastases and the timing of the relapse-free period.

Conclusions. Factors that affects the overall survival are the features of the histology of the primary lesion, multiplicity of metastatic lesions, RPA class and the synchronous nature of the metastasis. The median of overall survival of patients who did not receive after surgical treatment of a particular type of therapy was only 4 months. If to use the combined treatment (surgical treatment with the irradiation of the whole brain) median survival was 9-10,5 months (depending on the method of irradiation). When you use drug treatment the median overall survival was 11 months. In the complex treatment survival rates were highest 12 months.syndrome, significantly reduces body weight.

\section{Введение}

В Российской Федерации нет единого учёта случаев метастатического поражения ЦНС, в отличие от первичных опухолей головного мозга. Метастазы в головном мозге составляют 20-30\% всех внутричерепных новообразований [1]. По данным американской ассоциации по изучению метастазов в головном мозге, в США ежегодно диагностируется около 170000-200000 случаев метастазов в головном мозге, и год от года эта цифра растёт [2]. Данный факт связывают как с улучшением методов визуализации в виде использования информативных исследований, таких, как компьютерная и магнитно-резонансная томография (КТ и МРТ), так и с ростом продолжительности жизни онкологических больных, что предоставляет промежуток времени для развития метастатических очагов. Статистические исследования, проведенные США, показали, что прижизненная диагностика метастазов в общей популяции взрослых онкологических больных составляет 9,6\%, тогда как по данным аутопсий - 24-45\% [2,3,4]. Количество летальных исходов от метастатического поражения цНС достигает 70000 в год [5]. Средняя продолжительность жизни больных с метастатическим поражением головного мозга составляет 5-9.5 мес., количество больных переживших год после обнаружения метастазов в головном мозге не превышает $40 \%$, 5-летняя выживаемость - $10 \%$, полное излечение отмечается в единичных случаях [6].

$60 \%$ всех метастатических опухолей диагностируются у пациентов 50-70 лет, что совпадает с пиком заболеваемости злокачественными новообразованиями [7]. При этом, в детской онкологии метастатические опухоли головного мозга встречаются лишь у 6-12,5\% больных (наиболее часто метастазируют саркомы, нейробластомы и эмбриональные опухоли) [8,9].

В патогенезе метастазирования в целом играют роль 3 наиболее значимых фактора: накопление изменений в метастазирующей клетке, наличие благоприятного микроокружения органа-мишени, и завершение сложного каскада молекулярно-биологических событий, называемых «метастатический каскад" [10]. Метастазы попадают в головной мозг гематогенным путём. Около $20 \%$ сердечного выброса попадает в сосуды головного мозга, объясняя факт, что наиболее часто в головной мозг метастазируют опухоли легких. Большинство метастазов встречаются на границе между серым и белым веществом, где диаметр сосудов существенно сужен, что способствует опухолевой эмболии (единственным исключением является меланома, метастазы которой развиваются преимущественно в сером веществе) [11,12]. Мозговой кровоток омывает преимущественно гемисферы (80\%), затем - мозжечок и ствол мозга. Поэтому в $85 \%$ случаев внутримозговых метастазов обнаруживаются в больших полушариях, $10-15 \%$ - в мозжечке и $3 \%$ - в стволе мозга [11]. Крайне редко метастазы обнаруживаются в сосудистых сплетениях, шишковидной железе, гипофизе, зрительном нерве. Отдельной проблемой является карциноматоз мозговых оболочек, когда метастазы развиваются в мозговых оболочках, обнаруживаются при рутинном или проточном исследовании ликвора и метастазируют внутри центральной нервной системы.

Внутричерепные метастазы обычно развиваются в виде четко отграниченных округлых узлов, что позволяет проводить условно радикальное хирургическое вмешательство. Активированные клетки микроглии тканевые макрофаги, формируют четкую границу в виде вала между опухолью и веществом мозга [13]. Метастаз часто окружен зоной отека в результате нарушения гематоэнцефалического барьера в опухоли. Белки проникают из опухолевой ткани в окружающее вещество мозга и увеличивают в нем содержание воды. Отеку способствует повышенная проницаемость сосудов в результате действия VEGF (vascular endothelial growth factor) [14].

Обнаружены изменения метаболических реакций в перифокальной ткани, окружающей метастазы, которые проявляются снижением концентрации вита- 
минов-антиоксидантов (А и Е) и ростом концентрации продуктов перекисного окисления липидов. Глубина нарушения свободнорадикального метаболизма ткани, окружающей метастаз, зависит от их количества и характера первичной опухоли [15]

Течение заболевания при метастатическом поражении головного мозга чаще всего острое с быстрым возникновением и нарастанием симптомокомплекса поражения церебральных структур, что характерно для инсультоподобного варианта развития опухолей головного мозга.

Дифференциальная диагностика при метастатическом поражении головного мозга проводится с абсцессами, первичными опухолями мозга, лимфомами ЦНС, демиелинизирующими или воспалительными изменениями. Основой дифференциального диагноза является анамнез (так, одиночное объёмное образование в головном мозге у больного с онкологическим анамнезом в 95\% случаев является метастазом, и лишь в 5\% случаев - первичным новообразованием [7]) и МР-картина.

При магнитно-резонансной томографии метастатические фокусы лучше всего визуализируются на Т2-взвешенных изображениях [16]. Они имеют изоинтенсивный вид по отношению к мозговой ткани, но в режиме Т2 перифокальный отек хорошо очерчивает зону поражения (рис. 1 б). На томограммах, взвешенных по Т1 (рис. 1 а), метастазы изоинтенсивны или слабо гипоинтенсивны по отношению к белому веществу мозга и практически не визуализируются. В метастатических опухолях вне зависимости от размеров может определяться центральный некроз, гипоинтенсивный в режиме Т1 и гиперинтенсивный в режиме Т2. При внутривенном контрастном усилении отмечается выраженное повышение интенсивности сигнала от опухолей (рис. 1 в).

Золотым стандартом для диагностики метастазов в головной мозг является МРТ - исследование с внутривенным контрастным усилением, которое позволяет оценить локализацию, характер и число как супратенториальных, так субтенториальных поражений мозгового вещества.

Несмотря на столь высокие показатели заболеваемости данной патологией, в настоящее время нет единого мнения о тактике лечения пациентов с метастазами в головном мозге.

Больные, имеющие метастазы в головной мозг, по канонам онкологии относятся к группе онкологических больных с отдаленными метастазами, что требует комплексного подхода к их лечению. Выбор оптимального метода лечения к метастазам опухолей различной гистологической структуры, локализации, с учётом распространённости экстракраниального процесса является до конца не решённой задачей. Улучшение качества жизни, быстрый регресс неврологической симптоматики и достижение локального контроля являются прямыми задачами нейрохирургической службы.

Также в настоящее время нет единого мнения и не сформулирована тактика лечения больных с олиго- и множественными метастазами в головном мозге, не определены факторы, неблагоприятно влияющие на прогноз заболевания, знание которых позволило бы на догоспитальном этапе оценивать возможную эффективность планируемого лечения.

Целью настоящей работы стало обобщение опыта лечения больных с метастатическим поражением головного мозга. Мы поставили задачи оценить влияние на общую и безрецидивную выживаемость таких факторов, как гистологическое строение первичной опухоли, количество метастазов и их локализация, контроль первичного очага и экстракраниальных метастазов.

\section{Материалы и методы}

В ФГБУ МНИОИ им. П.А. Герцена Минздрава России с 2007 по 2013 гг было пролечено 268 больных с метастазами в головном мозге. Средний возраст составлял 55,8 лет (от 24 до 81 года), мужчин было 138 (51\%), женщин 130 (49\%). Распределение больных по нозологии представлено на рисунке 2. Наиболее часто метастазировали в головной мозг рак лёгкого - 90 больных (34\%), рак молочной железы - 71 больная (26\%), рак почки - 30 больных (11\%), коло-ректальный рак - 21 пациент (7,8\%). На долю других нозологий приходилось $11 \%$ пациентов.

По данным RTOG 1997 все пациенты с внутримоз-
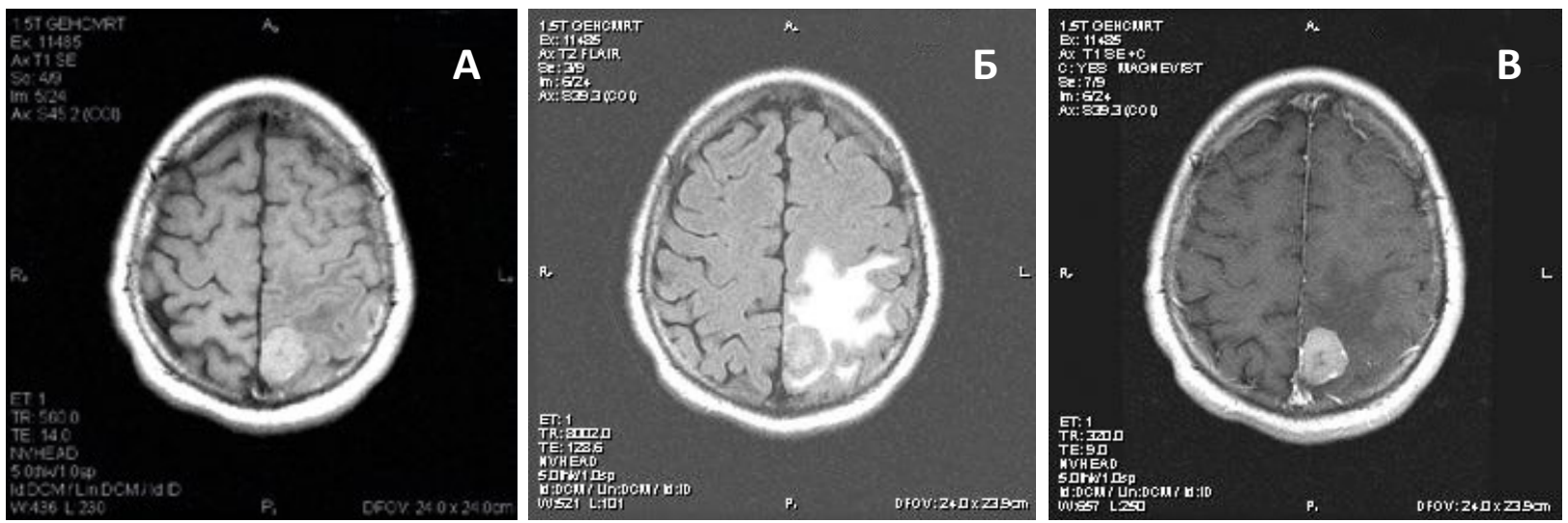

Рисунок 1. Магнитно-резонансная томограмма пациента с солитарным метастатическим поражением головного мозга. а) Т1 взвешенное изображение: очаг изоинтенсивен; б) Т2 взвешенное изображение. Очаг также изоинтенсивен и окружен зоной перифокального отека; в) Т1 взвешенное изображение с дополнительным контрастным усилением: патологическая ткань, накапливающая контрастное вещество, четко отграничивается от непораженной ткани мозга. 
говыми метастазами делятся на 3-и класса (Recursive partitioning analysis (RPA) of prognostic factors), в зависимости от индекса Карновского, контролируемости первичного заболевания, возраста, наличия экстракраниальных образований (таблица 1) [17]. В нашей группе к 1 RPA классу относились 68 (25,37\%) больных, к 2 RPA классу, встречавшемуся наиболее часто, 136 (50,75\%) больных, и к 3 RPA классу - 65 (24,25\%) пациентов.

Наиболее часто (185 больных, 69\%) метастазы обнаруживались в полушариях головного мозга, у 48 (17,9\%) пациентов был поражён мозжечок, у 33 пациентов (12,3\%) наблюдалось множественное поражение.

С нашей точки зрения важно отметить, что у 66 больных (24,6\%) было синхронное выявление первичной опухоли и метастаза в головном мозге, то есть метастатическое поражение явилось первым проявлением опухолевого процесса. у больных с метахронным выявлением внутримозгового метастазирования (2 и более месяца - 202 больных (75,4\%)) среднее время с момента диагностирования первичной опухоли составило 39 месяцев (2-245 мес.).

Перед началом лечения все больные проходили комплексное обследование. Выполнялось МРТ головного мозга с внутривенным контрастным усилением (при наличии противопоказаний - КТ с внутривенным контрастным усилением). Солитарный метастаз диагностирован у 164 (61,19\%) пациента, олигометастазы (2-3) - у 72 (26,87\%) больных, множественные метастазы (более 3) - у 32 (11,94\%) больных. У 162 (60,45\%) больных были выявлены экстракраниальные метастазы. Для 106 (39,55\%) больных метастатическое поражение головного мозга было единственным проявлением генерализации процесса. 17 больных (6,3\%) имели первичную множественность опухолей.

Всем пациентам на первом этапе лечения выполнялось хирургическое лечение в условиях нейрохирургического отделения МнИОИ им. П. А. Герцена с использованием микрохирургической техники по поводу метастатической внутримозговой опухоли.

С целью контроля радикальности удаления опухоли у 93 (34,7\%) больных использовался метод флуоресцентной навигации (ФД). У 66 (24,6\%) больных интраоперационно проводился сеанс фотодинамической терапии (ФДТ). Во всех наблюдениях для ФД и ФДТ использовался препарат Аласенс (гидрохлорид 5-аминолевулиновой кислоты (5-АЛК)), производства ФГУ «ГНЦ НИОПИК» по разработанной в МНИОИ им. П.А. Герцена методике [18]. 5-АЛК является предшественником гема, который, при избыточном введении в организм пациента, вызывает синтез и накопление эндогенного флюорохрома -
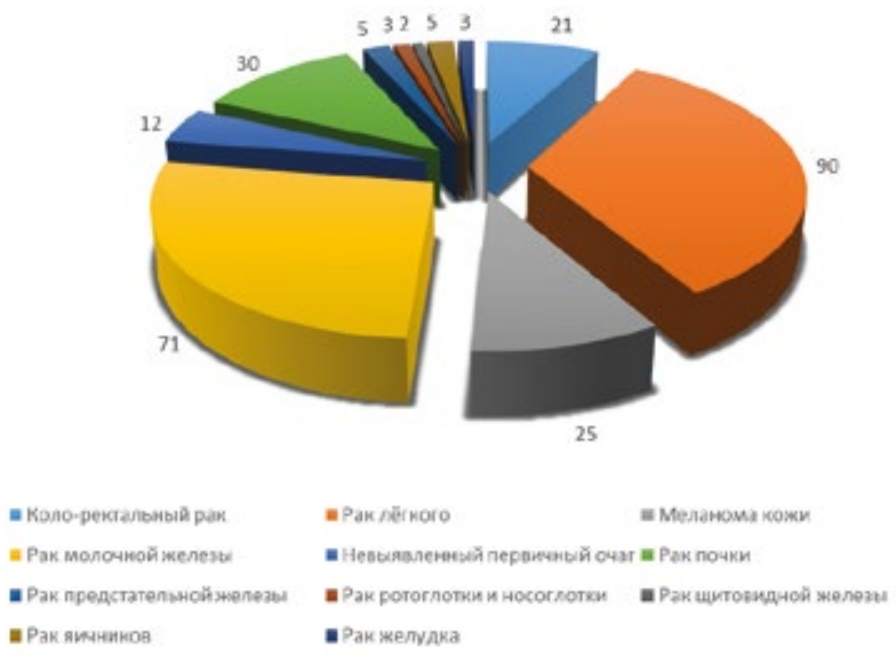

Рисунок 2. Распределение больных по первичному очагу.

Таблица 1

Определение RPA-классов

\begin{tabular}{l|l|l|l}
\hline $\begin{array}{l}\text { RPA классы и количество больных } \\
\text { Показатели }\end{array}$ & Класс 1 $(\mathrm{n}=68)$ & Класс 2 $(\mathrm{n}=136)$ & Класс 3 $(\mathrm{n}=65)$ \\
\hline Индекс Карновского, \% & $>70$ & $>70$ & $<70$ \\
\hline Контролируемость первичного заболевания & Контролируемо & Неконтролируемо & Любой статус \\
\hline Возраст & $<65$ & $>65$ & любой \\
\hline Наличие экстракраниальных метастазов & Нет & Есть & Любой статус \\
\hline
\end{tabular}




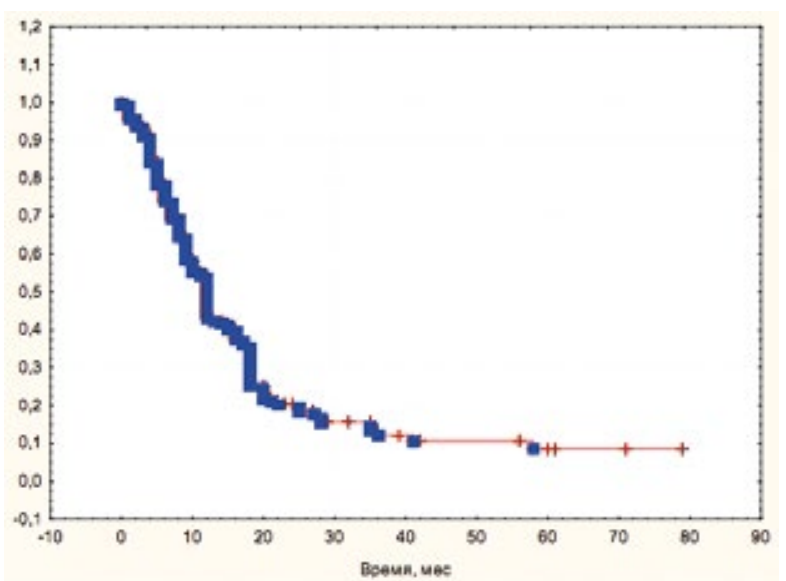

Рисунок 3.

Медиана общей выживаемости методом Каплана-Мейера

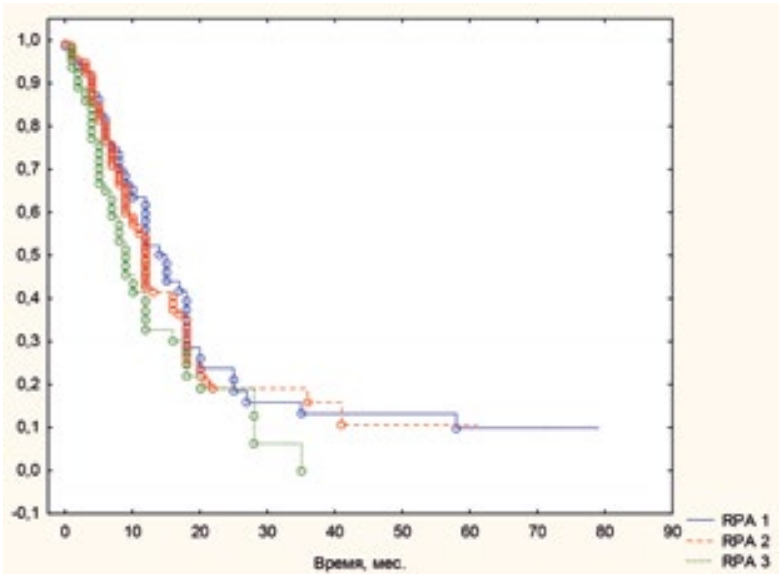

Рисунок 4. Медиана общей выживаемости методом КапланаМейера: RPA 1, 2, 3 классы.

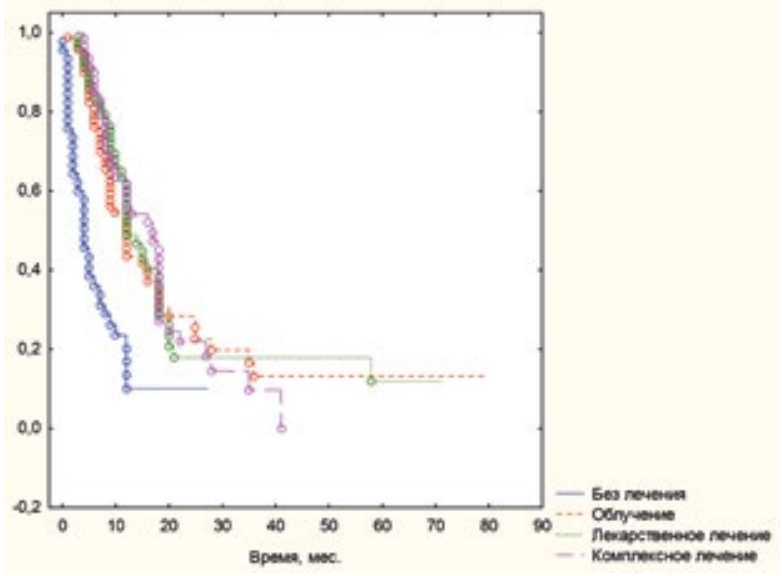

Рисунок 6. Медиана общей выживаемости методом КапланаМейера в зависимости от метода последующего лечения. протопорфирина IX в опухолевых клетках. Всем больным препарат Аласенс вводили путем приема внутрь в дозе 20 мг/кг за 2-2,5 часа до начала интубационного наркоза (за 3-4 часа до предполагаемого времени проведения ФД и ФДТ). Для проведения ФД использовалась флуоресцентная диагностическая установка: “D-Light AF System" Karl Storz (Germany) и операционный микроскоп Karl Zeiss. Для проведения ФДТ применялся полупроводниковый лазер ALOD-01 (Россия) с длиной волны 635 нм.

Контроль радикальности оценивался по данным МРТ или КТ с внутривенным контрастным усилением. У 212 $(79,1 \%)$ пациента удаление метастаза выполнено тотально. У 55 (20,9\%) больных констатировано субтотальное удаление.

\section{Результаты}

Тактика дальнейшего лечения вырабатывалась коллегиально на основании существующих российских и международных клинических рекомендаций. Больные

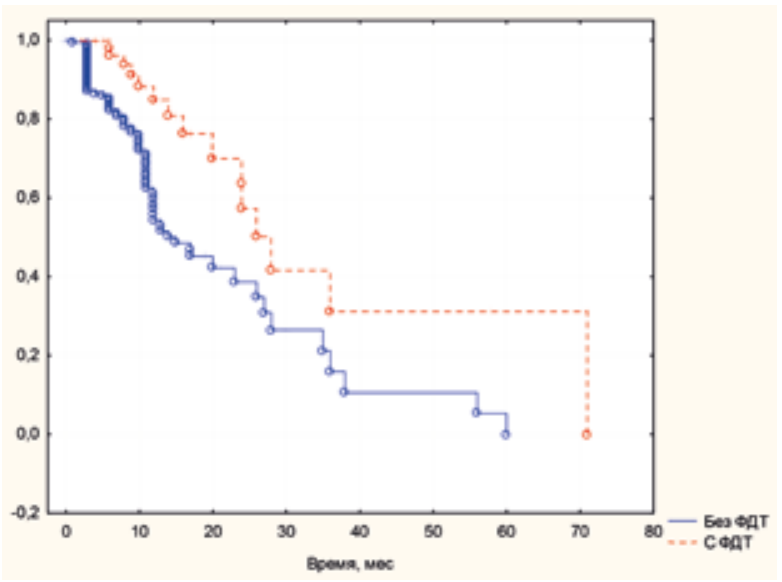

Рисунок 5. Медиана безрецидивной выживаемости методом Каплана-Мейера: группа 1 - без Фдт; группа 2 - с Фдт.

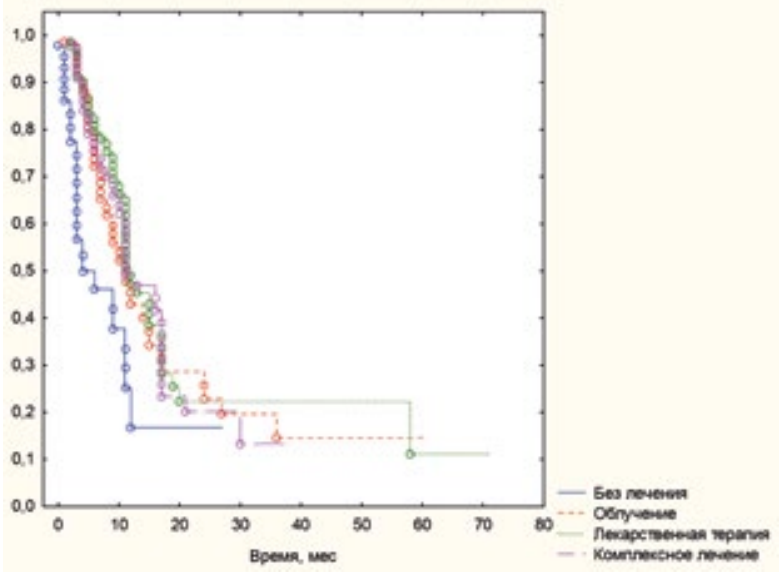

Рисунок 7. Медиана безрецидивной выживаемости методом Каплана-Мейера в зависимости от метода последующего лечения 
продолжали лечение как в МНИОИ, так и в других специализированных учреждениях. Период наблюдения за больными составил от 3 до 79 месяцев. Судьба пациентов отслеживалась при обследованиях в условиях МНИОИ, по телефонограммам, а также по данным онкодиспансеров. К моменту публикации жив 88 больной $(32,8 \%)$, умер 180 (67,2\%). У 120 (66,7\%) пациентов причиной смерти стала генерализация, у 25 (13,8\%) - неонкологические заболевания. Важно отметить, что лишь 11 (6,1\%) пациентов умерли от рецидива метастаза в головном мозге и 24 $(13,3 \%)-$ от появления новых очагов в головном мозге.

Данные анализировались с применением стандартных методик статистической обработки (программа Statistica 10). Медиана выживаемости среди всей группы больных с метастатическим поражением головного мозга составила 12 месяцев (рисунок 3).

Общая выживаемость достоверно зависела от RPA класса ( $p=0,06508)$. Так, если в RPA 1 классе она составляла 14 месяцев, то в RPA 2 и RPA 3-12 и 9 месяцев соответственно (рисунок 4).

Медиана общей выживаемости зависела от первичной опухоли. Так, наиболее длительная выживаемость наблюдалась у больных раком лёгкого (16 месяцев), неплохими представляются результаты лечения пациенток с метастазами рака молочной железы (12,0 мес.) и рака почки (12,4 мес). Низкие показатели общей выживаемости отмечались при меланоме (7 месяцев), колоректальном раке (8,3 месяца), метастазах из невыявленного первичного очага (5,0 мес).

Рецидив в зоне операции выявлен у 58 (21,6\%) больных. Безрецидивная выживаемость (медиана 11,0 месяцев) достоверно зависела от использованной ФДТ ( $p=0,00018)$, однако, зависимость от ФД не достоверна ( $p=0,14754)$ (рисунок 5). Медиана выживаемости при синхронном выявлении первичной опухоли и метастатического поражения головного мозга составляла 10,5 мес, при метахронном выявлении - 12 месяцев.

Нами были проанализированы показатели выживаемости после наиболее распространённых вариантов лечения. Так, медиана общей выживаемости больных,

\section{Список литературы:}

1. Лошаков В.А. Интракраниальные метастатические опухоли: Клиническая неврология под редакцией Коновалова А.НМ 2005; III:1: 402-408.

2. Palmieri, Diane, eds. Central Nervous System Metastasis, the Biological Basis and Clinical Considerations. New York: Springer; 2012

3. Posner J.B., Chernik N.L. Intracranial metastases from systemic cancer. Adv Neurol. 1978; 19: 579-592.

4. Nussbaum E.S., Djalilian H.R., Cho K.H., Hall W.A: Brain metastases: Histology, multiplicity, surgery, and survival. Cancer. 1996; 78: 1781-1788.

5. Langley R.R., Fidler I.J. The Biology of Brain Metastasis. Clinical Chemistry.2013; 59(1): 180-189.

6. Takeshima H., Kuratsu J., Nishi T. Prognostic factors in patients who survived more than 10 years after undergone surgery for metastatic brain tumors: report of 5 cases and review of the literature.Surg. Neurol. 2002; 58: 118123.

7. Raizer J.J., Abrey L.E., eds. Brain Metastases. Springer. 2007. p.2-3. DOI 10.1007/978-0-387-69222-7 не получавших после хирургического лечения иного вида терапии (44 больных, 16,4\%), составляла всего 4 месяца. При использовании комбинированного лечения (хирургическое лечение + лучевая терапия) медиана выживаемости составляла 9-10,5 месяцев (в зависимости от метода облучения). При применении лекарственного лечения медиана общей выживаемости составила 11 месяцев. При комплексном лечении, т.е. использовании химиотерапии и лучевой терапии показатели выживаемости были наиболее высокими - 12 месяцев (рисунок 6).

Безрецидивная выживаемость без дополнительного лечения составляла всего 3 месяца. После облучения она достоверно ( $p=0,00024)$ увеличивалась до 7,5 мес, после лекарственного лечения - 11 месяцев. При комплексном лечении безрецидивная выживаемость составляла 9 мес (рисунок 7).

\section{Выводы}

На основании опыта, накопленного нашим институтом, мы считаем, что рациональная хирургия метастазов опухолей в головном мозге может считаться методом выбора в лечении данных больных, что позволяет увеличить продолжительность жизни оперированным пациентам и улучшить качество их жизни.

Это позволяет относиться к хирургическому лечению как к основному методу в комбинированной терапии. Несомненно, проблема вторичного поражения головного мозга является больше биологической, чем хирургической, и тотальное удаление очага поражения не свидетельствует о выздоровлении пациента.

Факторами, влияющими на общую выживаемость являются особенности гистологии первичного очага, множественность метастатического поражения, RPA класс и синхронный характер метастазирования.

Лишь в 19,44\% случаев причиной смерти больных оказалось интракраниальное поражение. Наилучшие показатели выживаемости наблюдаются у больных, получавших системную терапию для контроля экстракраниального процесса и лучевую терапию для контроля внутримозговых метастазов.

8. Vannucci R.C., Baten M. Cerebral metastatic disease in childhood. Neurology. 1974; 24(10): 981-985.

9. Graus F., Walker R.W., Allen J.C. Brain metastases in children. J Pediatr. 1983; 103(4): 558-561.

10. Ротин Д.Л. Клинико-морфологические и молекулярно-биологические аспекты развития метастазов в головной мозг. Вопросы нейрохирургии им. Н.Н. Бурденко. 2012; 2: 70-76

11. Disibio G., French S.W. Mettastatic patterns of cancers: results from the large autopsy study. Arch Path Lab Med. 2008; 132: 931-939

12. Hwang Close T.P., Grego J.M., et al. Predilection of brain metastasis and gray and white matter junction and vascular border zones. Cancer. 1996; 77(8): 1551-1555.

13. He B.P., Wang J.J., Zhang X., et al. Differential reactions of microglia to brain metastasis of lung cancer. Mol Med. 2006; 12(7-8): 161-170.

14. Follmore C.M., Kuperwasser C. Human breast cancer cell lines contain stem-like cells that self renew. Breast Cancer Res. 2008; 140: $62-73$. 
15. Погорелова Ю.А., Франциянц Е.М., Балязин И.В., Комарова Е.Ф., Черярина Н.Д. Состояние свободнорадикальных процессов в ткани опухолей мозга и метастазов рака различной локализации в головной мозг. Известия высших учебных заведений. Северо-кавказский регион. 2011; 3: 112-116

16. Коновалов А.Н., Корниенко В.Н., Пронин И.Н. Магнитно-резонансная томография в нейрохирургии. М.: Видар, 1997: 125-126

17. Gaspar L., Scott C., Rotman M., et al. Recursive partitioning analysis (RPA) of prognostic factors in three Radiation Therapy

\section{References:}

1. Loshakov V.A. Intrakranial'nye metastaticheskie opukholi: Klinicheskaya nevrologiya pod redaktsiei Konovalova A.N. M.: 2005; III:1: 402-408. (Russian)

2. Palmieri, Diane, eds. Central Nervous System Metastasis, the Biological Basis and Clinical Considerations. New York: Springer; 2012

3. Posner J.B., Chernik N.L. Intracranial metastases from systemic cancer. Adv Neurol. 1978; 19: 579-592.

4. Nussbaum E.S., Djalilian H.R., Cho K.H., Hall W.A: Brain metastases: Histology, multiplicity, surgery, and survival. Cancer. 1996; 78: 1781-1788.

5. Langley R.R., Fidler I.J. The Biology of Brain Metastasis. Clinical Chemistry.2013; 59(1): 180-189.

6. Takeshima H., Kuratsu J., Nishi T. Prognostic factors in patients who survived more than 10 years after undergone surgery for metastatic brain tumors: report of 5 cases and review of the literature.Surg. Neurol. 2002; 58: 118123.

7. Raizer J.J., Abrey L.E., eds. Brain Metastases. Springer. 2007. p.2-3. DOI 10.1007/978-0-387-69222-7

8. Vannucci R.C., Baten M. Cerebral metastatic disease in childhood. Neurology. 1974; 24(10): 981-985.

9. Graus F., Walker R.W., Allen J.C. Brain metastases in children. J Pediatr. 1983; 103(4): 558-561.

10. Rotin D.L. Clinico-morphological and molecular-biological aspects of cerebral metastases development Zhurnal 'Voprosy nejrokhirurgii imeni N.N. Burdenko' 2012; 2: 70-76. (Russian)

11. Disibio G., French S.W. Mettastatic patterns of cancers: results from the large autopsy study. Arch Path Lab Med. 2008; 132: 931-939

Информация об авторах:

1. Зайцев Антон Михайлович - к.М.н., заведующий отделением нейрохирургии МНИОИ им. П.А. Герцена - филиал ФГБУ «НМИРЦ» Минздрава России

2. Куржупов Михаил Иванович - к.М.н., научный сотрудник отделения нейрохирургии МНИОИ им. П.А. Герцена - филиал ФГБУ «НМИРЦ» Минздрава России

3. Потапова Елена Александровна - врач-невролог отделения нейрохирургии МНИОИ им. П.А. Герцена - филиал ФГБУ «НМИРЦ» Минздрава России

4. Кирсанова Ольга Николаевна - младший научный сотрудник отделения нейрохирургии МНИОИ им. П.А. Герцена филиал ФГБУ «НМИРЦ» Минздрава России
Oncology Group (RTOG) brain metastases trials. Int J Radiat Oncol Biol Phys. 1997; 37:745-751.

18. Куржупов М.И., Лошаков В.А., Филоненко Е.В., Зайцев А.М., Ханмурзаева А.Г. Интраоперационная флюоресцентная диагностика и фотодинамическая терапия у больных с метастатическим поражением головного мозга. Вопросы нейрохирургии им Н.Н. Бурденко. 2012; 2: 50-57.

12. Hwang Close T.P., Grego J.M., et al. Predilection of brain metastasis and gray and white matter junction and vascular border zones. Cancer. 1996; 77(8): 1551-1555.

13. He B.P., Wang J.J., Zhang X., et al. Differential reactions of microglia to brain metastasis of lung cancer. Mol Med. 2006; 12(7-8): 161-170.

14. Follmore C.M., Kuperwasser C. Human breast cancer cell lines contain stem-like cells that self renew. Breast Cancer Res. 2008; 140: 62-73.

15. Pogorelova Yu.A., Frantsiyants E.M., Balyazin I.V., Komarova E.F., Cheryarina N.D. Sostoyanie svobodnoradikal'nykh protsessov v tkani opukholei mozga i metastazov raka razlichnoi lokalizatsii v golovnoi mozg. Izvestiya vysshikh uchebnykh zavedenii. Severokavkazskii region. 2011; 3: 112-116. (Russian)

16. Konovalov A.N., Kornienko V.N., Pronin I.N. Magnitnorezonansnaya tomografiya $v$ neirokhirurgii. M.: Vidar, 1997: 125-126. (Russian)

17. Gaspar L., Scott C., Rotman M., et al. Recursive partitioning analysis (RPA) of prognostic factors in three Radiation Therapy Oncology Group (RTOG) brain metastases trials. Int J Radiat Oncol Biol Phys. 1997; 37:745-751.

18. Kurzhupov M.I., Loshakov V.A., Filonenko E.V., Zaitsev A.M., Khanmurzaeva A.G. Intraoperative fluorescent detection and photodynamic therapy in patients with metastatic cerebral lesions. Zhurnal 'Voprosy nejrokhirurgii imeni N.N. Burdenko'. 2012; 2: 50-57. (Russian).

Information about authors:

1. Zaytsev Anton Mikhailovich - PhD, head of neurosurgery department of P. Hertsen MORI

2. Kurzhupov Mikhail Ivanovich - PhD, researcher of neurosurgery department of P. Hertsen MORI

3. Potapova Elena Alexandrovna - neurologist of neurosurgery department of P. Hertsen MORI

4. Kirsanova Olga Nikolaevna - junior researcher of neurosurgery department of P. Hertsen MORI

\section{Оформление ссылки для цитирования статьи:}

Зайцев А.М., Куржупов М.И., Потапова Е.А., Кирсанова О.Н. Лечение метастатического поражения головного мозга. Исследования и практика в медицине. 2015; 2(2): 8-14. DOI: 10.17709/2409-2231-2015-2-2-8-14

Zaytsev A.M., Kurzhupov M.I., Potapova E.A., Kirsanova O.N. Treatment of metastatic brain lesion. Issled. prakt. Med. 2015; 2(2): 8-14. DOI: 10.17709/2409-2231-2015-2-2-8-14

Конфликт интересов. Все авторы сообщают об отсутствии конфликта интересов.

Conflict of interest. All authors report no conflict of interest. 